\title{
Sobre instituições e culturas escolares
}

Regarding school institutions and cultures

Acerca de instituciones y culturas escolares

Edilene Alexandra Leal Soares

Universidade Federal do Triângulo Mineiro (Brasil)

https://orcid.org/0000-0002-9703-018X

http://lattes.cnpq.br/8990017947382113

edilenealexandra@yahoo.com.br

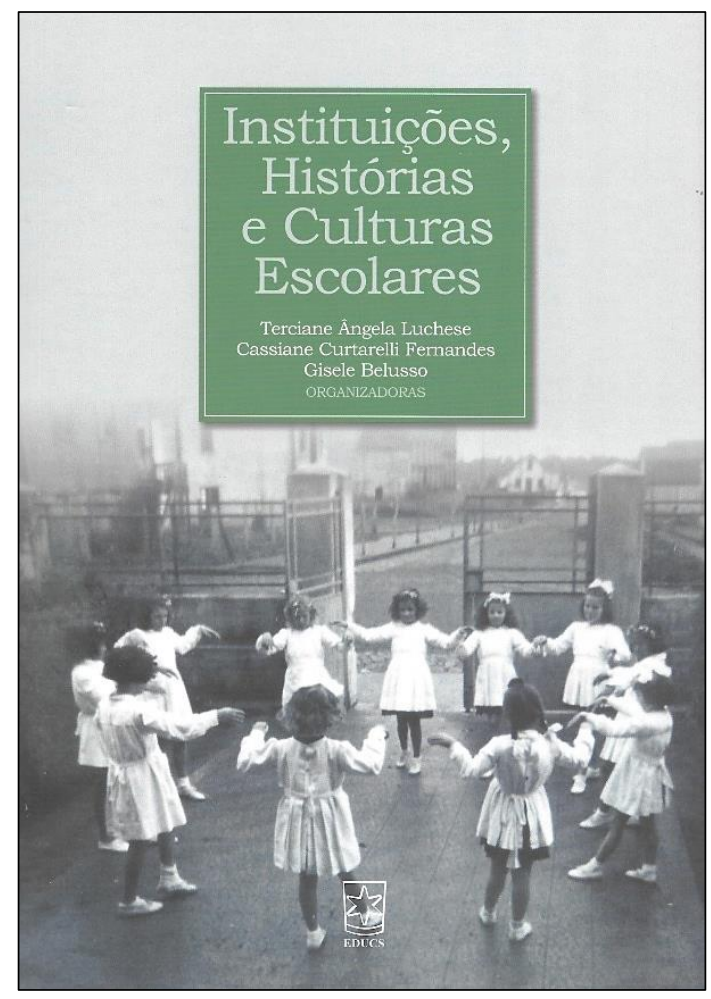

LUCHESE, Terciane Ângela; FERNANDES, Cassiane Curtarelli; BELUSSO, Gisele (Org.). Instituições, Histórias e Culturas Escolares. Caxias do Sul: Educs. 2018. 294p. 
O livro Instituições, Histórias e Culturas Escolares é uma coletânea que reúne autores que realizaram análises de diversos objetos, os quais contribuem sobremaneira para os interessados em conhecer a História da Educação brasileira, sendo que a presente publicação trata de estudos realizados em instituições escolares tanto em âmbito local de Caxias do Sul/RS quanto regional e oportuniza aos leitores uma gama de conhecimentos fundamentais para os que apreciam a Historiografia da Educação.

O prefácio do livro ficou a cargo de Wenceslau Gonçalves Neto, que valorizou, sobretudo, a importância da investigação coletiva em torno dos aspectos local e regional desenvolvidas em linhas de pesquisa em História da Educação em programas de pósgraduação em Educação, no que foi complementado pelo texto de apresentação redigido pelas organizadoras, no qual elas apresentaram as atividades de pesquisa desenvolvidas pelo Grupo de Pesquisa História da Educação, Imigração e Memória (Grupheim) do Programa de PósGraduação em Educação da Universidade de Caxias do Sul, entre 2009 e 2017, das quais este livro é um dos resultados.

No primeiro capítulo, "História e historiografia das instituições escolares: aspectos conceituais, teóricos e metodológicos" os pesquisadores Décio Gatti Jr e Gisele Cristina do Vale Gatti proporcionam uma compreensão histórica do surgimento das Instituições Escolares no contexto da Modernidade. Didaticamente, os autores propiciam um entendimento de como no decorrer da História a concepção de educação foi sendo modificada. Pensadores como Rousseau foram trazidos à tona para proporcionar ao leitor a importância de relacionar aspectos conceituais de educação de cada contexto considerando a relação educação e sociedade. Os aspectos metodológicos também são discutidos de forma clara e objetiva o que permite melhor apreensão das alterações surgidas no campo História da Educação. A proposta realizada pelos autores elucida um marco conceitual e metodológico que proporciona compreender o tempo e espaço elencados como ponto de análise para a historiografia da história das instituições escolares.

No segundo capítulo, a pesquisadora Terciane Ângela Luchese menciona os aspectos teóricos e metodológicos para a pesquisa com as Instituições Escolares identificando as diversas possibilidades de investigação com fontes que enriquecem o estudo proposto. A autora em referência enfatizou as Culturas Escolares o que permite ampliar o entendimento desse objeto, considerando-o no sentido plural, uma vez que cada instituição possui sua especificidade e que envolve também os sujeitos (tanto internos quanto externos à instituição) os quais colaboram no processo educativo, por conseguinte para a apreensão da temática abordada.

No terceiro capítulo, Vanessa Lazzaron apresenta "A História do Colégio do Carmo de Caxias do RS e as rotinas escolares (1908-1933)". A autora realiza sua análise a partir de aspectos inerentes à fundação da instituição, bem como às práticas desenvolvidas por discentes e docentes. Cabe ressaltar, que o estudo contribui para apreender os aspectos concernentes a uma instituição confessional e evidencia as diferentes possibilidades para a pesquisa das instituições escolares. 
O quarto capítulo, de Roseli Maria Bergozza, intitula-se, "De Escola Complementar a Escola Normal: histórias da primeira instituição pública para formação de professores na cidade de Caxias do Sul (1930-1961)", no qual analisa a primeira instituição oficial pública daquele município, perpassando pelas várias denominações que a instituição teve ao longo desse período. A autora pesquisou diversas fontes que evidenciam a importância da instituição para a preparação de professores primários no município de Caxias do Sul.

O quinto capítulo, de Valéria Alvez Paz Foner, destaca “Aspectos Históricos da Educação Feminina no cotidiano do Colégio São Carlos (1936-1971)”. A autora apresenta a gênese dessa instituição, que pertenceu à Congregação das Irmãs Missionárias de São Carlos Borromeo - Scalabrinianas e, a partir da documentação analisada, evidencia o diaa-dia da instituição, o que permite a compreensão da educação destinadas às alunas. Ademais, trata-se de uma pesquisa que contribui para o entendimento da colonização italiana naquela região do Brasil.

Posteriormente, no sexto capítulo, Gabriele Vieira Neves apresenta "Percursos históricos da educação de surdos em Caxias do Sul: 55 anos da Escola Helen Keller”, aborda esse ramo da educação especial, bem como as concepções difundidas sobre a surdez, que influenciaram as práticas educativas destinadas àquele público. Neste sentido, o referido estudo possui significativas contribuições para apreender o processo de educação disseminada aos surdos e vislumbra para futuras pesquisas, ainda incipientes em várias localidades e ou regiões do Brasil.

No sétimo capítulo, Daniele Uglione Fabbrin aborda também a educação especial, especificamente de crianças com deficiência intelectual e múltipla, correlacionando com as concepções pedagógicas que embasaram a criação da Associação de Pais e Amigos dos Excepcionais - mais conhecida por sua sigla, APAE, no município de Caxias do Sul no período das décadas de 1970 e 1980.

No oitavo capítulo, Júlia Tomedi Poletto, escreveu "Pulso de ferro e coração de ouro: práticas da cultura escolar presentes no Colégio Sagrado Coração de Jesus (1956-1972)”, instituição situada em Bento Gonçalves/RS. A autora enfatiza as práticas escolares e as relaciona à Educação Religiosa, o que é evidenciado como disciplina que deu ênfase à Cultura Escolar no âmbito daquela instituição.

Em seguida, no nono capítulo, Larissa Camacho de Carvalho realizou análises a partir de excertos do documento - "Revista comemorativa dos 55 anos do Instituto Federal do Rio Grande do Sul - IFRS" e inter-relacionou com outras fontes, com o objetivo de apreender as questões históricas da referida instituição, o que perpassou desde a gênese até o momento em que se tornaria o Instituto Federal do Rio Grande do Sul, denominado Campus Bento Gonçalves. O referido estudo elege os aspectos estruturais/arquitetônicos, bem como demais informações que compõem um corpus documental para entendimento da História Cultural engendrada no referido estudo. 
O décimo primeiro capítulo, escrito por Cassiane Curtarelli Fernandes, "De Grupo Escolar Rural de Nova Vicenza a Grupo Escolar Farroupilha: Uma catedral bela e majestosa (Farroupilha/RS, 1927-1944), aborda o processo de criação e de implantação do primeiro grupo escolar de Farroupilha/RS. A autora realizou um retrospecto histórico dos grupos escolares em âmbito local, regional e nacional e, posteriormente, a partir de um corpus documental bem diversificado, tratando do objeto pesquisado em articulação com contexto de modernização educacional do município.

Por conseguinte, o último capítulo, elaborado por Marina Matiello, tratou do "Colégio Regina Coeli: sujeitos do ensinar e do aprender de uma escola confessional católica (1948-1969)" localizada em Veranópolis/RS. A autora detalha as especificidades da instituição que iniciou como confessional católica e, posteriormente, passou ao estatuto de instituição comunitária. A autora realizou incursões que antecederam ao recorte temporal da pesquisa, discutindo, desde 1917, o papel educacional exercido pela Congregação das Irmãs de São José. Conforme salienta a autora, o colégio permaneceu sob a direção da referida congregação até o ano de 1976.

O livro Instituições, Histórias e Culturas Escolares é uma obra que permite aos leitores conhecer a Historiografia da Educação, especificamente das Histórias de Instituições Escolares locais e regionais de Caxias do Sul/RS e assim apreender a relação intrínseca da instituição e das pluralidades de culturas que permeiam o âmbito educacional. 